\title{
Camellia Oil
}

National Cancer Institute

\section{Source}

National Cancer Institute. Camellia Oil. NCI Thesaurus. Code C65283.

The oil extracted from the seeds of Camellia sinensis. Camellia oil is used in skincare preparations for it anti-oxidant properties. Camellia oil can also be used as a cooking oil. 